\title{
Implementation of a log book for senior house officers undertaking general professional training
}

With the full support of the Collegiate Trainees' Committee and after over two years planning within the Department of Postgraduate Educational Services, the Court of Electors have recommended that a $\log$ Book to assist General Professional Training for senior house officers will be implemented from February 1998.

This Log Book (Personal Training File) is trainee-owned, and expected to assist

(1) the three- and six-month appraisal with the Educational Supervisor;

(2) weekly supervision;

(3) giving appropriate career advice including when to take the MRCPsych examination. The use of the Log Book is not a component of Summative Assessment.

A Working Party chaired by Dr David Newby piloted the Log Book in four different schemes, and in the light of this experience it was modified into its present form.

The implementation of the Log Book is as follows:

Coordinating Tutors will be sent a Log Book Induction Pack and a copy of the Log Book before the end of the year and will then be asked to order the requisite number of Log Books from the College to ensure distribution to trainees by February 1998.

It is expected that the Log Book will be used regularly by Educational Supervisors and College Tutors in the way outlined above. The extent to which this target is achieved will be monitored through the trainees' representative on the Collegiate Trainees' Committee and by the Education Committee.

It is confidently anticipated that the use of the Log Book will improve training standards and it is within that spirit that the Convenor of an Approval Team will make a general enquiry about the extent of its use - or misuse.

An evaluation form is contained within the $\mathrm{Log}$ Book, and this information will be used to revise the $\log$ Book in the light of experience.

I believe this Personal Training File will facilitate more optimum training and education at a General Professional Level and may therefore also assist subsequent Specialist Training. 